\title{
The conscious human ecological experience, conscious design, and the evolution of the built environment
}

\author{
R. B. Dunavant IV \\ Gypsy Build, Regenerative Revolution, USA
}

\begin{abstract}
I have set out to develop a simple tool to use within the seemingly complex field of sustainable building design and construction. In a world of perceived complexities, complex issues, and conventional thought patterns it seems that simplicity is key, the key, in solving these interconnected and complex problems that our designers are forced to face in our current time. We must understand that our species is embarking on one of the most creative and innovative times in human history and as a result has room now for the development of creative and innovative strategies to combat these problems. This is largely in part due to the fact that our species is being presented with problems that have only recently surfaced and are completely new. As designers we must truly be able to stand back, observe the problem(s) objectively as an interconnected system, and be able to do so with a different perspective. The Conscious Human Ecological Experience is the act of accepting that we are connected to this planet, that we are an evolution of this planet, and that we are involved with this planet and the ecological systems, cycles and patterns that this planet possesses. Conscious Design is the use of this awareness and this acceptance as a tool within the design and redesign of the built environment. This understanding and this new design methodology will help propel the built environment and our species as a whole into a time of transformation, a time of innovation, and a time of balance that our species has yet to witness.
\end{abstract}

Keywords: design thinking, sustainability, consciousness, evolution, built environment, systems thinking, biophilia, biophilic design, biomimicry. 


\section{The conscious human ecological experience}

To become conscious, to become aware, to self reflect. What a beautiful thing, what a beautiful part of the human experience. To become conscious of our connection to this planet and our connection to the ecological systems, cycles, and patterns that she possesses. To become conscious of the growth of our species through the many years of her existence. To become conscious of our involvement with her growth to understand that we have grown alongside her and in doing so are involved with her, her systems, and are very much a part of her. She, this planet, has made an attempt to become conscious of herself, to become aware of herself, and to reflect on herself. This attempt was the creation of us. We are a conscious minded relative of the planet herself. We are her, she is us, and this must be understood.

I have inherited my great grandfather's hair color, hair thickness, and his height. It is also said that I have my great grandfather's adventurous spirit. His wont to wander and wonder is also nestled deep within me. I was not able to be raised in his presence and never knew him. In my younger years, being raised solely by family members who worked in the field of engineering, I was interested only in music and literature which for many years made me a "black sheep" within my family. My grandmother's brothers and sisters, who I have not known in my lifetime, are artists and musicians and their love and passion for the arts in its many forms is nestled deep within me as well. I was born and raised in the southeastern part the US and yet, I have always had a calling to the western states. The majority of my family, at least half, originate from the southwestern, the western, and the northwestern states of the US.

We call them the laws of nature - natural operating system that helps this planet move forward which in turn helps us move forward. Just as I have inherited certain traits from members of my family whom I have not known within my lifetime, our species as a whole has inherited this natural operating system that this planet holds within. As this planet is in a constant pursuit of homeostasis we can say that this planet is in constant pursuit of balance. Our species is in constant pursuit of a feeling that we call happiness and/or a feeling of comfort as well as pursuit of security within our lives. In reality our species is in constant pursuit of balance. We share this "trait", this pursuit of balance, with this planet at almost any level and at any moment within our human experience.

As we possess this trait of a natural operating system within us, we then must know what we are supposed to be surrounded by. We know how our surrounding environment is supposed to feel, how it is supposed to sound, and so on and so forth with the remaining senses that we possess. This is part of our human ecological experience and to become aware of these traits that have been passed down from the planet herself, is the conscious human ecological experience. To become conscious, to become aware, and to self reflect. To know that when we ask nature for the solutions to our planets most pressing environmental issues we are asking ourselves.

For instance, in my studies, my research, and my own life experience I have witnessed that a large percentage of the homeless population in the US arises in 
the morning facing the sun, wherever the sun may rise in one particular place in that moment on this planet. I see that within us we are holding some very interesting and key traits that inform our decisions and yet we are not looking into ourselves for them. How many of you wake in the morning facing the direction of the sun?

When I close my eyes and envision the natural world I see a dew filled forest at dawn, a slowly rolling meadow, and I see a desert landscape at dusk. I see regenerative systems, restorative cycles, and I see the beauty of true efficiency. When I close my eyes and envision the natural world, I see resilience, the ability to adapt, and I see the reasons that we are here.

During various speaking engagements at sustainable building design and construction conferences I have conducted a very simple experiment. I tell the audience to close their eyes, clear their heads, and to envision nature. After a short time, I ask the audience to share what they see. It is astonishing to me what the audience shares. The audiences paint very similar pictures of the natural world.

What the audiences are envisioning does not seem all that interesting and yet it is. This is interesting for two reasons. The first reason being that when the audience is asked to envision the natural world the audiences are then able to describe the natural world and even if the descriptions are fairly elementary the descriptions are still there. The second reason that the audience describing the natural world in this way is of interest is the fact that every single participant is able to describe an object in the natural world or a natural landscape without physically being present within a natural landscape. Again, every single participant in several audiences is able to describe that natural world. We, all of us, every person, can call to our conscious minds several descriptions of the natural world at will. I absolutely understand the fact that the majority of us have been involved in "nature" at some point in our lives, some of us more than others. Yet there are some of us that are very rarely exposed to the natural world and some of us have never been exposed to any environment other that the built environment. When I have conducted this exercise with children that have lived their lives solely within a dense urban environment they have been able to describe a natural landscape or an object that would only thrive in a natural landscape. Again, this is an elementary description and yet this is a very interesting observation. Again, our species is holding this ability, or this trait, within us and again we are able to call this to our conscious mind at will.

As a result of our species having a conscious mind we are therefor able to make rational decisions. We are able to decipher the difference between right and wrong, moral and immoral, what one is going to where on a certain day, and how we raise our children. One very amazing act that can be accomplished by our species with our conscious mind is change. We are able to change the way that we are able to think. We are fully able to change our perspective of our entire lives. With hard work and persistence we are able to change our bad habits, our old patterns, and the functionality of our systems. We are able to change the future. The result of this ability to change is that the future is the future that we create, and because our species is able to alter and completely 
change our perception we are in turn able to alter and change the future, our future.

In his book "The Biology of Belief" Bruce H. Lipton [1] writes "When I provided a healthy environment for my cells they thrived; When the environment was less than optimal, the cells faltered. When I adjusted the environment, the sick cells revitalized". The surrounding environment can affect and alter our cells, and therefore our genetic code. Just the act of telling yourself that you love yourself every day and then believing this you love yourself will in turn be passed down as an inherited trait to your children. Your children can inherit the act of loving themselves. Self-love would be intertwined in their genetic code. This is because you were able to change your perspective from something like self-loathing to self-love, therefor changing the environment surrounding your child while his or her development while in the womb. The surrounding environment in the case of the Conscious Human Ecological Experience is exactly this, a change in perception, a change in the way that we think. A change in our perception in which we become conscious, aware, and accept the fact that we are connected to this planet in every way at any moment can drastically change our perception on how we act on a daily basis towards this planet and ultimately ourselves. This shift in the way of accepting our very real connection to this planet will therefor change our relationship to this planet. This change in perspective in the sustainable building and design industry will absolutely enhance the health and wellbeing of our dwellings, the built environment as a whole, and we will finally be able to honor the generations to come.

In her book "Thinking in Systems" Donella H. Meadows [2] writes "A system is more than the sum of its parts. It may exhibit adaptive, dynamic, goal seeking, self-preserving, and sometimes evolutionary behavior." She then goes on to write "Many of the interconnections in systems operate through the flow of information. Information holds systems together and plays a great role in determining how they operate." Our mind is a system, our lives are systems, and we are a system ourselves. These systems are then embedded in a much larger system. We are a part of this planets evolutionary system as well as the planets ecological systems. We have unfortunately changed our role in this system from being involved in a balancing-feedback loop in which the goal is balance, to a reinforcing-feedback loop which fathers exponential growth, which leads to an inevitable collapse. When we realize our roles in this abrupt switch from a balancing-feedback loop to a reinforcing-feedback loop, when we become conscious and aware that we have done so, we are then able enough to re-involve ourselves with this planets balancing-feedback loop, homeostasis, the pursuit for balance, and the ecologies that this planet possesses.

In his book "Being Peace" Thich Nhat Hanh [3] writes of the "Second Mindfulness Training". He writes, "Aware of the suffering created by attachment to views and wrong perceptions, we are determined to avoid being narrowminded and bound to present views. We shall learn and practice non-attachment from views in order to be open to others' insights and experiences. We are aware that the knowledge we presently possess is not changeless, absolute truth. Truth is found in life, and we will observe life within and around us in every moment, 
ready to learn throughout our lives." This being said, we must release our attachment to the ways that things have always been done. We must realize that the laws that have been set forth by our species in large part go against the laws that this planet set forth. As a result of this release and realization we will be able to approach our designs with a truly open mind. We must understand that entering into a gentle collaboration with our individual selves, the entirety of our species, and at the same time with the planet herself will be the most efficient and effective way to approach the issues that are to be faced within realm of sustainable building design and construction.

\section{Conscious design}

When a design is to be implemented on a future site and instead of merely going through the typical design motions we must sit with the design for a moment. We must conceptualize the design, we must see the design for what it really is, what we really want the design to be, and what the site wants the design to be. From the designs inception we must enter into a conscious design charrette. Before we let the led holder touch the trace paper we must first become centered and balanced with ourselves, even if this centering and balance only comes for a moment, we must still work to do so. Below is an example of how to approach our design(s) with an awareness and in a conscious manner.

Let us arrive at the future site where we are to implement a design. We are arriving at this future site within our minds at this moment, not our physical bodies. Before we enter fully into this conscious design charrette we must contemplate what this design will provide for the present generations, future generations, and the surrounding environments. We want our design free these people, this place, this planet from stresses and pain. We want our design free these people, this place, this planet from animosity, from trouble, from oppression. We want our design look after these people, this place, this planet with ease. We want our design teach these people on this place, this planet the way to true happiness.

After this we will close our eyes and envision the natural world. We will simply paint a picture of the future site in our minds. This is it, nothing more and nothing less. We will simply sit with this, with ourselves, for a moment. We will witness this picture that we have painted in our minds of the natural world and this picture will begin to evolve slowly.

Let us place ourselves on the future site. Let us become aware of the feeling of the site and let us become conscious of the feelings and the emotions that arise within us while placing ourselves upon the site. Let us place ourselves on this future site during a rain event, a snow event, or any weather event. How does this feel, what emotions and thoughts arise as a result? How will we involve the future design, the inhabitants, and the surrounding environments with the hydrological systems, cycles, and patterns that activate the future site?

Let us place ourselves on the future site and envision ourselves facing the sun. How does this affect our minds and our bodies? How do we want this site to affect our minds and our bodies? What emotions or feelings arise within us while 
doing so? While sitting on this future site let us observe, interact, and become aware of the readily available materials on the future site. When the available materials have been observed let us sit with the materials, the idea of the materials, and become aware of the impact that the removal or displacement of the selected materials from the future site will affect the future design, the inhabitants, and the surrounding environments.

Let us place ourselves on the future site and become aware of the feeling and the movement of the air. Let us become aware of the quality of the air along with the quantity. Might there be straight line winds? Burst of winds? Or no air movement at all? How will the air movement, or lack thereof, affect the future design, the inhabitants, and the surrounding environments?

Let us become aware of the location of the future site. How does this future site affect the surrounding environments and the surrounding communities as well as the entirety of ecosystems that this planet possesses, both near and far? Let us become aware of the sites past, the sites present, and sites future. How will the location of this future site affect generations to come? How will this future site change and adapt over time? Or will this future site recycle back into the surrounding ecosystems and the surrounding communities? How will the future design of this future site project compassion, happiness, and consciousness? How will this future design of this future site promote a transformation from the then to the now, and from the present to the future?

Now we must turn this conscious design charrette into a physical site assessment. We must go to the future site, truly be with the future site, and we must devour every aspect of the site and every moment that we are allowed to be with the site. We must understand that to be with this site is an honor, an opportunity to provoke thought and true change in this world, and a luxury for our species to be able to reconstruct the earth beneath our feet. When we are on this future site we must feel and listen to the site. We must approach the future site with the same open-mindedness and non-attachment that we approached the future site within the conscious (nonphysical) design charrette.

In her book "Thinking in Systems" Donella H. Meadows writes "A system is an interconnected set of elements that is coherently organized in a way that achieves something. If you look at the definition closely for a minute, you can see that a system must consist of three kinds of things: elements, interconnections, and a function or purpose." She then goes on to write "A tree is a system, and a forest is a larger system that encompasses subsystems for trees and animals".

This being said, we must understand that this future site is already a system that is embedded in a larger system. Perhaps this future site is a greenfield that has been relatively untouched by our species. We must honor this and again realize that this site is embedded in a system. With our design we must only slip into the flow of the system that is already in operation on this site as well as the system that encompasses this site. We must enter into this site with only a gentle collaboration with our design into the already natural, organic, and absolutely efficient flow of this site and this system. Our design and/or redesign must be or become completely involved with the ecological systems, cycles, and patterns 
that are operating on this site. To disrupt these systems, these cycles, and/or these patterns has the possibility of effects on the future that we are to be unaware of at the designs inception.

When we approach a design with the understanding of interconnection, of involvement, and of compassion we will produce a design that is truly in line with this planets alignment which in turn will realign our species with this planet.

\section{The evolution of the built environment}

Imagine entering into a space that called you into it, lured you in by suggestion only. Imagine entering into a space and falling into a feeling of warmth, a feeling of loving embrace. Imagine entering into a space that calms you down and reduces the stress of the day. Imagine entering into a space that gives you a feeling of peace.

Imagine entering into a space that is built with earth. A space that is in and of the earth. Imagine standing in this space. We slowly run your fingers along the wall, we press your bare feet onto the floor, and we feel the cool temperature of the earth that this space is made of. We sit in this space and it is as though we are sitting on a fallen tree in the middle of the forest. We feel that we absolutely want to be there. The sounds, the feeling of the air on our face, the smell of the pines, the smell of the soil. These are all there, they have been designed into this space, and we know that they are there.

Imagine that we have slowly walked to a window that is positioned in this space. We are now looking out onto the city streets. The streets resemble the flow and movement of the river. The people walking the city streets resemble schools of fish. They are slipping in and out of each other and then almost being washed ashore to their destinations. We look from this window. We look for a view of the city's skyline. We look and see a canopy of green that covers the city. It is as though the city itself has been grown. The city has been grown from out of the banks of the river that the city streets were designed to resemble. The city is a city that has been grown, nurtured, and fed. This city is a city in bloom.

Imagine the we are looking past the skyline of the city. Imagine looking past the city itself. The city looks as though it melts into the natural landscape, the natural landscape looks as though it melts back into the city. There is no line of demarcation, there is no difference between the city and the natural landscape. The city and the natural landscape have finally become one. They operate as an interconnected system. The city and the natural landscape are involved with each other in a gentle collaboration. They share each other's cycles, their patterns, and breed a true balance. They breed love, compassion, and above all they breed consciousness.

Conscious design is the transformation of the built environment from the mechanical to the natural, from rigidity to a flow, and from corners to curves. Conscious design is the involvement and the reintroduction of the built environment, the dwellings that are held within, and our species as a whole with the ecological systems, cycles, and patterns that this planet showers upon us 
every day. Conscious design is the beginning of the evolution of design. An evolution that has yet to be witnessed within the building design and construction industry. As we begin to embrace ourselves, we will begin to embrace what this planet has to offer, and as a result this planet will again be able to embrace us. From this point forward our designs will be approached with the understanding of interconnection, the projection of compassion, and above all our designs will be approached with a conscious mind.

\section{References}

[1] Lipton, B.H., Ph.D. “The Biology of Belief”, p. 19, 2008

[2] Meadows, D. H., "Thinking in Systems", pp. 13-15, 2008

[3] Hanh, T. N., "Being Peace", Second Mindfulness Training, 2005 